This document is the accepted manuscript version of the following article:

Ehrhart, T., Steiger, R., Lehmann, M., \& Frangi, A. (2020). European beech (Fagus sylvatica L.)

glued laminated timber: lamination strength grading, production and mechanical properties. European Journal of wood and wood Products. https://doi.org/10.1007/s00107-020-01545-6

\title{
European beech (Fagus sylvatica L.) glued laminated timber: Lamination strength grading, production and mechanical properties
}

\author{
Thomas Ehrhart 1) 2), René Steiger 2), Martin Lehmann ${ }^{3)}$, Andrea Frangi 1) \\ 1) ETH Zurich, Institute of Structural Engineering, Stefano-Franscini-Platz 5, 8093 Zurich, Switzerland \\ 2) Empa - Swiss Federal Laboratories for Materials Science and Technology, Structural Engineering Research \\ Laboratory, Ueberlandstrasse 129, 8600 Duebendorf, Switzerland \\ 3) Bern University of Applied Sciences, Institute for Materials and Wood Technology, Solothurnstrasse 102, 2504 Biel, \\ Switzerland
}

"corresponding author: ehrhart@ibk.baug.ethz.ch; +41 446339150

\section{Abstract}

This paper presents the results of extensive investigations on the lamination strength grading, the production and the mechanical properties of European beech (Fagus sylvatica L.) glued laminated timber (GLT). Based on the analysis of potential influencing parameters on strength and stiffness as well as subsequent tension tests parallel to the grain on single boards, a combined visual/machine approach for grading the raw material into tensile strength classes T50, T42, T33 and T22 was developed. Boards strength graded with the developed procedure were then finger-jointed by a Swiss GLT producer and the strength of the finger joints was investigated by means of tension and bending tests. The strength and durability of the bonding was investigated and verified by means of tensile-shear and delamination tests. It could be shown that the required finger-joint and bondline strengths for GLT of strength classes GL40 and GL48 can be achieved, but that the process parameters for finger jointing (in particular the geometrical properties of the finger joint profile) have to be optimized in order to be able to produce GLT of strength class GL55. Finally, an extensive experimental testing campaign was performed to investigate the mechanical properties of European beech GLT produced based on the strength grading rules and production techniques developed before. Bending, tensile and compressive parallel to the grain, as well as shear tests were carried out on GLT specimens of strength classes GL40, GL48 and GL55 in different sizes in terms of crosssection and length. Based on these investigations and complementing numerical simulations, characteristic strength and stiffness values and formulae for consideration of size effects in bending, tension and shear were determined.

\section{Keywords}

European beech glued laminated timber, Fagus sylvatica L., mechanical properties, strength grading

\section{Introduction}

To date the share of European beech (Fagus sylvatica L.) amounts to $18.1 \%$ of the total timber stock in the Swiss forests. Along with Norway spruce (Picea abies Karst., 43.7\%), European beech is the second most common tree species and by far the most common hardwood species in Switzerland, followed by ash (Fraxinus excelsior L., 4.1\%), maple (Acer pseudoplatanus L., 3.1\%), and oak (Quercus robur L., 1.9\%) (BAFU 2018). In a study conducted between 2004 and 2006 (Brändli 2010), the species European beech, Norway spruce, ash, maple and oak contributed $18.1 \%, 44.1 \%, 3.7 \%$, $2.9 \%$ and $2.2 \%$ respectively, to the total timber stock in Switzerland.

Hardwoods in general are expected to benefit from the changing climatic conditions in Central Europe and their share of the forests is predicted to increase further in future (Lindner et al. 2010). However, dry summers in the years 2018 and 2019 also led to partly severe damage concerning beech trees dying off because of drought in Central Europe. In the course of the European Research Project SUSTREE, a decline in the species European beech by 2100 has been forecasted (Bundesforschungszentrum für Wald bfw Österreich 2019).

The long-term goal of sustainable forest management, a balance between growth and harvest, cannot be achieved today, especially regarding hardwoods. In 2017, the yearly increase in the 
hardwood forest stock of 3.45 million $\mathrm{m}^{3}$ in Switzerland was in contrast to a commercial use and mortality of the hardwood stock of only 2.56 million $\mathrm{m}^{3}$ (BAFU 2018). Additionally, the actually still predominant use of hardwoods for energy purposes (70\% of the hardwood harvested in 2017$)$ is rated unfavourable by the Swiss economy, forestry agencies and federal offices.

The construction sector has been identified as an economically and in terms of climate policy interesting option for using beech wood with its excellent mechanical properties. Numerous ongoing or completed research projects in Austria (e.g. Frühwald and Schickhofer 2004; Hübner 2013; Linsenmann 2016), Germany (e.g. Glos and Lederer 2000; Frühwald et al. 2003; Blaß et al. 2005; Westermayr et al. 2018), Slovenia (e.g. Plos et al. 2018) and Switzerland contribute to a steadily growing knowledge of the characteristics and peculiarities of this wood species with regard to its application for construction purposes.

In Switzerland, the Swiss Federal Office for the Environment (FOEN) launched the programme Aktionsplan Holz. The main objective of the programme is to ensure that wood from Swiss forests is provided, processed and recycled in a sustainable and resource-efficient manner. Resource policy thus makes a major contribution to forest, climate and energy policy (BAFU 2017). As part of this research and innovation programme, a project was launched in 2015 under the lead of the Structural Engineering Research Laboratory of Empa, in collaboration with ETH Zurich and the Bern University of Applied Sciences BFH/AHB in Biel. The aim of the project was to investigate the entire production chain of glued laminated timber (GLT) made of European beech wood, as well as to determine the mechanical properties of the product and to contribute to the implementation of the findings in relevant standards. A survey among designers, conducted before launching the project, revealed that highly stressed columns, beams and trusses in residential, office and industrial buildings provide the biggest potential for the application of beech GLT in load-bearing structures. The research project focussed on European beech GLT of strength classes GL40, GL48 and GL55. In pilot projects, GL40 and GL48 grade GLT had been successfully produced by the industrial project partner neue Holzbau $A G$ (Lungern, Switzerland) and applied in practice. In order to be able to evaluate the full potential of the raw material, the investigations also involved the strength class GL55. The paper gives an overview on the results of this extensive research project and shows that the GLT strength classes targeted in the project offer the possibility to expand the currently increasing share of modern timber construction at the expense of mineral and metallic building materials.

\section{Lamination strength grading}

\subsection{Relevant indicators}

Naturally grown wood has to be strength graded when intended to be used for structural purposes, i.e., the mechanical properties have to be estimated based on the assessment of non-destructively measurable indicators. Indicators applicable to strength grading (i) shall be highly correlated with the target parameters (strength and stiffness), (ii) shall be easily and reliably identifiable by appropriate non-destructive means, and (iii) shall be quantifiable (Ehrhart 2019). All investigations described in the following were conducted on boards with cross-section dimensions of $160 \times 25 \mathrm{~mm}^{2}$. Preliminary investigations of the industrial project partner producing the GLT had shown that the width of the boards can be chosen simply based on the capacities in terms of size of the machines involved in the production process. However, the thickness of the boards, from the point of view of economic efficiency aimed at being shifted to a value as high as possible, was found to experience limitations due to the productions process. For thicknesses of 30 and $35 \mathrm{~mm}$ distortions formed when drying the boards led to problems during bonding of the lamellas since the pressure available in the bonding press was not sufficient to compensate the distortions. In addition, from experience in practice (also with softwood glulam) it is known that internal stresses in glued-laminated structural members exceeding a certain limit can provoke premature formation of cracks and hence, compromise the durability. 


\subsubsection{Visual indicators}

The following visual indicators were investigated, i.e., their presence, location and dimension were documented and their influence on the tensile strength and stiffness of single laminations was evaluated:

- Knot area ratio (KAR) \& total knot area ratio (tKAR) (e.g. BS 4978, 1996);

- Fibre deviation (Fig. 1a);

- Wavelike annual ring pattern (Fig. 1b);

- Red heart.

Whereas the size of knots and knot groups was quantified by means of the parameters knot area ratio KAR and the total knot area ratio tKAR respectively, the indicators fibre deviation (Fig. 1a), wavelike annual ring pattern (Fig. 1b) and red heart were only documented qualitatively. Boards with visually appearing fibre deviations were permitted but were not allowed to be assigned to the highest visual grade (Table 1). A more detailed description of the visual indicators evaluated during the strength grading process can be found in Ehrhart et al. (2016).
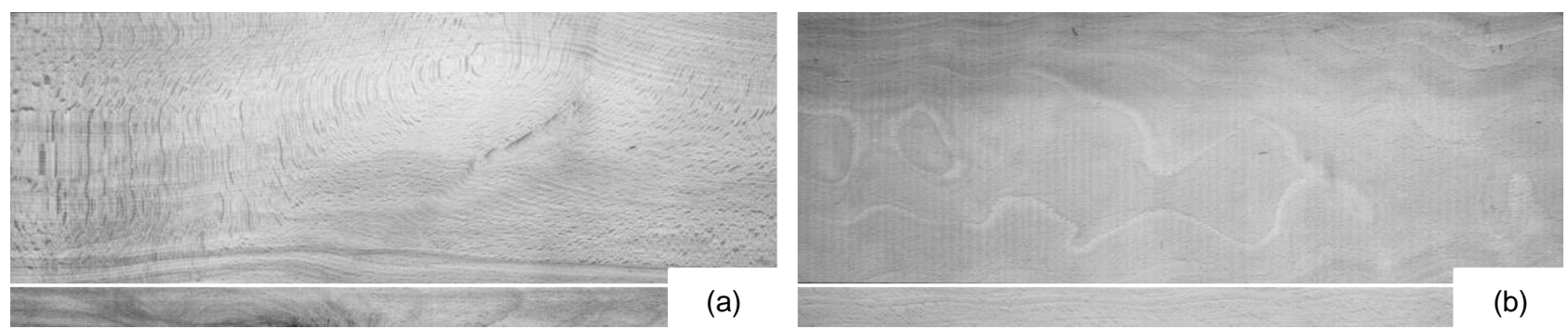

Fig. 1 Example of boards with fibre deviation (a) and wavelike annual ring pattern (b).

\subsubsection{Physical indicators}

The bulk density $(\rho)$ and the first natural frequency $\left(f_{0}\right)$ were measured in order to be able to determine the dynamic modulus of elasticity MOE $\left(E_{\text {dyn }}\right)$. The two devices ViScan V2.8 (by MiCROTEC) and MTG Timber Grader (by Brookhuis) were used. Based on the first natural frequency $f_{0}$, the length of the lamination $l_{l}$, and the board's bulk density $\rho$, the dynamic MOE $E_{\text {dyn }}$ was calculated with Equation 1. Depending on the actual wood moisture content $(u)$, the resulting densities were adjusted to the reference moisture content, which had been set to $u_{\text {ref }}=8 \%$ (EN 384, 2019) in this study due to the primarily intended application of beech GLT for indoor construction. Adjusting the dynamic modulus of elasticity to the reference moisture conditions followed the finding and recommendations by Unterwieser and Schickhofer (2011).

$$
E_{\mathrm{dyn}}=4 \cdot f_{0}^{2} \cdot l_{\ell}^{2} \cdot \rho
$$

\subsection{Verification by means of tension tests}

Tension tests according to EN 408 (2012) were carried out on 294 European beech timber boards and the influence of the visual and physical indicators determined during the strength grading process on the tensile strength $\left(f_{t, 0}\right)$ and the static tensile $\operatorname{MOE}\left(E_{t, 0}\right)$ parallel to the grain was evaluated. The tensile strength was calculated based on the ultimate force $\left(F_{\max }\right)$ and the lamination's width $\left(w_{\ell}\right)$ and thickness $\left(t_{l}\right)$ by means of Equation 2 . The tensile MOE was calculated using Equation 3 based on the displacements $(d)$ measured over a length of $I_{\text {meas }}(=$ $\left.5 \times W_{\ell}=800 \mathrm{~mm}\right)$ at force levels corresponding to $10 \%\left(F_{1}\right)$ and $40 \%\left(F_{2}\right)$ of the expected ultimate force $F_{\max }$.

$$
f_{\mathrm{t}, 0, \mathrm{l}}=\frac{F_{\text {max }}}{w_{\ell} \cdot t_{\ell}} \quad(2) \quad E_{\mathrm{t}, 0, \mathrm{l}}=\frac{l_{\text {meas }} \cdot\left(F_{2}-F_{1}\right)}{w_{\ell} \cdot t_{\ell} \cdot\left(d_{2}-d_{1}\right)}
$$


The resulting tensile MOE was adjusted to the reference moisture content $\left(u_{\text {ref }}=8 \%\right.$ ) according to EN 384 (2019). For the tensile strength, no equation for adjustment is specified in EN 384 (2019) since the tensile strength parallel to the grain is not subject to marked changes with changing moisture content (Hoffmeyer 1995). Further information on the test setup and the applied measurement data recording system is available in Ehrhart et al. (2016).

\subsection{Strength grading criteria}

Based on correlation analyses, the knots, the fibre deviation and the dynamic MOE were identified to have the largest influence on the target parameters tensile strength and MOE. Consistent with findings by Frühwald and Schickhofer (2004) and Aicher and Ohnesorg (2011), no significant influence of red heart was found.

Based on the analysis of the indicators relevant for strength and stiffness, criteria for the combined visual/machine strength grading of European beech timber boards into the strength grades T50, T42, T33 and T22 were developed. The criteria were calibrated based on the 294 European beech timber boards tested. In Table 1, the visual and physical criteria are summarised. Additional criteria regarding curvature, cracks and wane, which are mainly of importance for the production of GLT, may be adopted from DIN 4074-5 (2008).

The resulting $5 \%$-fractile values of tensile strength $\left(f_{\mathrm{t}, 0,05}\right)$ and mean values of $\mathrm{MOE}\left(E_{\mathrm{t}, 0, \text { mean }}\right)$ parallel to the grain for the strength grades are summarised in Table 2. The characteristic values were determined assuming lognormal distribution. The parameters making the lognormal distribution fitting the experimental results best were estimated with the maximum likelihood method $(\mathrm{mlm})$. It can be seen that the actual $5 \%$-fractile values of tensile strength are very close to the targeted values. Further information on the correlation analyses performed when developing the strength grading rules are available in Ehrhart (2019).

Table 1 Criteria for combined visual and machine strength grading of European beech boards into strength classes T22, T33, T42 and T50.

\begin{tabular}{lcccc}
\hline & \multicolumn{4}{c}{ Visual grade } \\
\hline Visual criteria & Vis. 1 & Vis. 2 & Vis. 3 & Vis. 4 \\
\hline Knot and bark inclusion & tKAR $\leq 0.05$ & tKAR $\leq 0.1$ & tKAR $\leq 0.2$ & tKAR $\leq 0.3$ \\
Fibre deviation & Not perm. & Permitted & Permitted & Permitted \\
Wavelike annual ring pattern & Not perm. & Permitted & Permitted & Permitted \\
Red heart & Permitted & Permitted & Permitted & Permitted \\
Discolouration & & & \\
$\quad$ Hardness not reduced & Permitted & Permitted & Permitted & Permitted \\
Hardness reduced & Not perm. & Not perm. & $\leq 0.2$ We & $\leq 0.2$ We \\
Insect damage & Not perm. & Not perm. & Not perm. & Not perm. \\
Pith & Not perm. & Not perm. & Not perm. & Not perm. \\
\hline Minimum MOE Edyn (GPa) & Strength grade (based on visual grade and Edyn) \\
\hline Visual grade & T50 & T42 & T33 & T22 \\
\hline Vis. 1 & $\geq 16.5$ & $\geq 14.0$ & $\geq 12.0$ & $\geq 10.0$ \\
Vis. 2 & - & $\geq 16.5$ & $\geq 14.0$ & $\geq 10.0$ \\
Vis. 3 & - & $\geq 18.0$ & $\geq 16.5$ & $\geq 10.0$ \\
Vis. 4 & - & - & - & $\geq 15.0$ \\
\hline
\end{tabular}

It could be shown that strength grades up to T50 can be achieved with European beech timber boards when applying the visual and physical indicators presented in Table 1. For a better estimation of strength and a more efficient strength grading, information on the (local) fibre orientation with higher precision is necessary. However, as mentioned, for example by Aicher et al. (2001), Frühwald 
and Schickhofer (2004) and Schlotzhauer et al. (2018), so far no method for the automated detection and documentation of fibre orientation has been available for European beech wood. Hence, in the course of the project, a new non-contact method for the determination of fibre direction in European beech wood, based on the analysis of the wood rays, was developed (Ehrhart et al. 2017, 2018a, b). This method allows for highly accurate predictions of the fibre orientation, especially for flat-sawn and semi-rift-sawn boards. Thus, the method can contribute to a more efficient strength grading of the raw material and the implementation of strength grades even higher than T50.

Table 2 Mean and $5 \%$-fractile values of lamination tensile strength $\left(f_{t, 0, \ell}\right)$ and $\operatorname{MOE}\left(E_{t, 0, \ell}\right)$ and finger joint bending $\left(f_{\mathrm{m}, \mathrm{j}}\right)$ and tensile strengths $\left(f_{\mathrm{t}, \mathrm{j}}\right)$ grouped by strength grade.

\begin{tabular}{|c|c|c|c|c|c|c|c|}
\hline & Property & Symbol & Unit & T50 & T42 & T33 & T22 \\
\hline \multirow{6}{*}{ 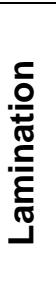 } & Number of tension tests & $n$ & - & 64 & 82 & 45 & 60 \\
\hline & Tensile strength, mean value & $f_{t, 0, \ell, \text { mean }}$ & $\mathrm{MPa}$ & 90.3 & 71.1 & 61.0 & 47.4 \\
\hline & Tensile strength, $5 \%$-fractile value & $\mathrm{f}_{\mathrm{t}, 0, \ell, 05}$ & $\mathrm{MPa}$ & 55.1 & 43.8 & 32.6 & 21.8 \\
\hline & Number of MOE measurements & $n$ & - & 43 & 43 & 19 & 37 \\
\hline & Tensile MOE, mean value & $E_{\mathrm{t}, 0, \ell, \text { mean }}$ & $\mathrm{GPa}$ & 16.8 & 15.4 & 14.4 & 13.7 \\
\hline & Tensile MOE, $5 \%$-fractile value & $E_{\mathrm{t}, 0, \ell, 05}$ & $\mathrm{GPa}$ & 15.0 & 12.6 & 12.0 & 11.3 \\
\hline \multirow{8}{*}{ 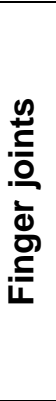 } & Number of bending tests & $n$ & - & 29 & 30 & 31 & - \\
\hline & Bending strength, mean value & $f_{\mathrm{m}, \mathrm{j}, \text { mean }}$ & $\mathrm{MPa}$ & 85.9 & 83.3 & 78.9 & - \\
\hline & Bending strength, $5 \%$-fractile value & $f_{m, j, 05}$ & $\mathrm{MPa}$ & 66.8 & 66.1 & 65.2 & - \\
\hline & Number of tension tests & $n$ & - & 36 & 46 & 48 & - \\
\hline & Tensile strength, mean value & $f_{\mathrm{t}, \mathrm{j}, \text { mean }}$ & $\mathrm{MPa}$ & 73.4 & 62.0 & 59.1 & - \\
\hline & Tensile strength, $5 \%$-fractile value & $f_{\mathrm{t}, \mathrm{j}, 05}$ & $\mathrm{MPa}$ & 52.2 & 43.7 & 43.5 & - \\
\hline & Ratio between $f_{\mathrm{m}, \mathrm{j}, \text { mean }}$ and $f_{\mathrm{t}, \mathrm{j}, \text { mean }}$ & - & - & 1.17 & 1.34 & 1.34 & - \\
\hline & Ratio between $f_{\mathrm{m}, \mathrm{j}, 05}$ and $f_{\mathrm{t}, \mathrm{j}, 05}$ & - & - & 1.28 & 1.51 & 1.50 & - \\
\hline
\end{tabular}

\section{Production of European beech GLT}

In general, the process steps in the production of beech GLT do not differ from those for softwood GLT: Logs are sawn, boards are dried, strength graded, finger-jointed, planed and bonded on the faces. However, in order to minimize cracking due to internal stresses occurring during the production process, a smaller lamination thickness (in this project: final thickness $t_{t}=25 \mathrm{~mm}$ ) as well as a wood moisture content, which already during production approximately corresponds to the later equilibrium moisture content (in this project: $8 \pm 2 \%$ ), were chosen.

When launching the project, it has been agreed on with the industrial partner producing the glulam that beside information on the type of adhesive products applied to finger jointing and bonding of the laminations, the process parameters are kept confidential.

\subsection{Finger jointing}

Since being of limited length when produced in the sawmills, European beech boards are joined longitudinally by finger joints. The strength of these joints plays a central role regarding the loadbearing capacity of GLT elements, especially in components subjected to tensile stress and laminations located in the tensile zone of beams. The strength of the finger joints was investigated by researchers at the Bern University of Applied Sciences BFH/AHB in Biel. In the following, the conducted tests are briefly summarised and the main results are presented. Further information is available in Lehmann et al. (2018).

The finger-jointed specimens were produced on a production line for softwood GLT (i. e. without optimising the geometrical properties of the finger joints for hardwood GLT) with a one-component polyurethane adhesive. The parameters of the adhesive application and the pressing process were adjusted for beech wood according to the experience of the project partner neue Holzbau AG (Lungern, Switzerland) in order to achieve satisfying performance of the finger joints. The crosssection dimensions of the laminations after planing were $150 \times 20 \mathrm{~mm}^{2}$ in the preliminary 
investigations and $150 \times 25 \mathrm{~mm}^{2}$ when producing the GLT beams to be investigated. To get a full representation of the material quality with regard to density and dynamic MOE, the tested specimens were equally chosen from the three strength classes T50, T42 and T33. However, it was made sure that zones with knots or with visually appearing fibre deviations were located at least $15 \mathrm{~cm}$ away from the finger joints.

The finger joint strength was assessed by means of 90 bending tests and 130 tension tests performed according to EN 408 (2012). The bending tests were conducted displacement-controlled; the tensile tests were carried out force-controlled. In Table 2, the resulting bending strengths $\left(f_{\mathrm{m}, \mathrm{j}}\right)$ and tensile strengths $\left(f_{\mathrm{t}, \mathrm{j}}\right)$ of the tested finger joints are shown grouped by T-class. For all grades, the finger joint tensile strengths exceed the boards' tensile strengths. Further information on the test setups and the results are provided by Clerc et al. (2017) and Lehmann et al. (2018).

\subsection{Bonding}

During the GLT production, the laminations were bonded using a one-component polyurethane adhesive and a primer, following the findings of investigations regarding appropriate bonding procedures conducted by the project partners Henkel Engineered Wood Adhesives and BFH/AHB Biel (Clerc et al. 2017). The chosen adhesive system exhibited sufficient strength in the tensile shear tests in the dry (A1) and wet state (A4) according to EN 302-1 (2013). The delamination behaviour proved to meet the requirements specified in EN 15425 (2017) when tested according to EN 302-2 (2017). Further information on the investigations of the bond line strength of European beech GLT specimens bonded with different adhesive systems and varying the production parameters can be found in Clerc et al. (2017) and Lehmann et al. (2018).

\section{Experimental investigations on European beech GLT}

The experiments on GLT specimens were carried out at Empa Dübendorf and ETH Zürich. The test programme consisted of full-scale testing of European beech GLT specimens subjected to bending, tension parallel to the grain, compression parallel to the grain and shear. In order to be able to quantify the influence of the size of the stressed volume on the mechanical properties (size effect, e.g. Weibull, 1939), the tested specimens differed not only with regard to strength class (GL40, GL48 and GL55) but also in terms of size, i.e., cross-section area and length. Thus, equations for the quantification of the size effect could be deducted from the experiments. To keep the costs for the specimens as low as possible, the reference height for the test campaign was chosen $400 \mathrm{~mm}$. Data analysis was conducted assuming normal distribution of the density and lognormal distribution of strength and stiffness, i.e., MOE and shear modulus. The parameters making the respective distribution fitting the experimental results best were estimated with the maximum likelihood method (mlm).

\subsection{Bending strength and MOE}

\subsubsection{Material and methods}

Four-point bending tests according to EN 408 (2012) were performed on European beech GLT beams with heights of $200 \mathrm{~mm}$ (width $w=120 \mathrm{~mm}), 400 \mathrm{~mm}(w=160 \mathrm{~mm}), 600(w=160 \mathrm{~mm})$ and $800 \mathrm{~mm}(w=180 \mathrm{~mm})$. Thus, the span varied between $(18 \times 0.20=) 3.60 \mathrm{~m}$ and $14.40 \mathrm{~m}$. Specimens of the strength classes GL40c (with outer $50 \%$ of the cross-sections consisting of T33 grade laminations and inner $50 \%$ of the cross-section consisting of T22 grade laminations), GL48c (T42/T22) and GL55c (T50/T33) were investigated (Fig. 2). 

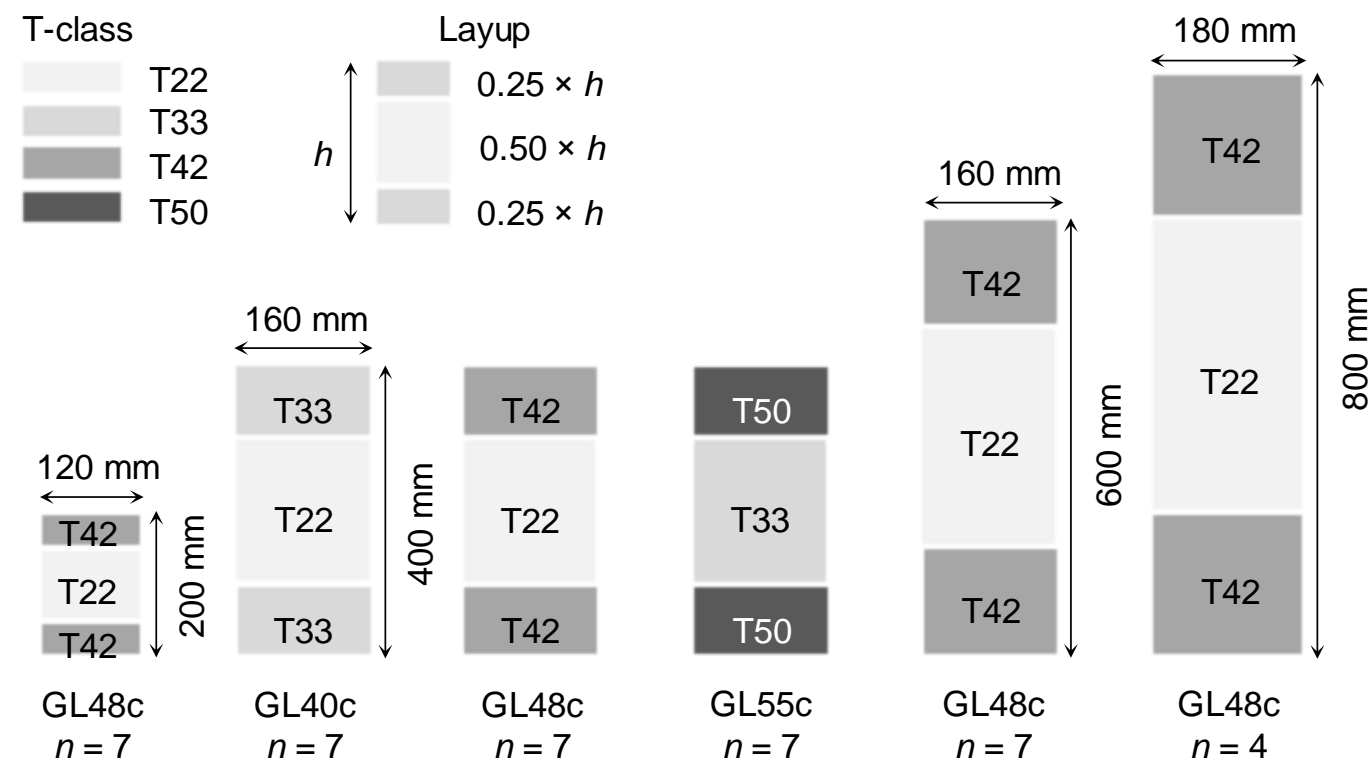

Fig. 2 Sizes and cross-section layups (used T-classes) of the specimens investigated in four-point bending tests.

Seven specimens were tested per series. In each test, the local $\left(E_{\mathrm{m}, \mathrm{loc}}\right)$ and global MOE $\left(E_{\mathrm{m}, \mathrm{glob}}\right)$, and the bending strength $\left(f_{\mathrm{m}}\right)$ were determined according to EN 408 (2012). In the tests on beams with heights of 600 and $800 \mathrm{~mm}$, additionally the shear modulus $\left(G_{\mathrm{g}}\right)$ was determined. $E_{\mathrm{m}, \text { loc }}$ was assessed based on deflection measurements in the neutral axis on both lateral sides of the beams. To prevent the sensors from damage, deflection measurements relative to the strong floor on top of the beams were used to determine $E_{\mathrm{m}, \mathrm{glob}}$. Hence, the measured deflections include deformations perpendicular to the grain due to respective compression stresses at the supports (Bogensberger et al. 2006). This is why the global MOE, since being affected by the test and the measurement set up, is known to be a stiffness indicator rather than a material property.

\subsubsection{Results and discussion}

The resulting bending strength $\left(f_{\mathrm{m}}\right)$ and local MOE $\left(E_{\mathrm{m}, \mathrm{loc}}\right)$ determined in the four-point bending tests are summarised in Fig. 3. In the boxplots, the upper and the lower margin of the boxes are defined by the first and third quartiles. The horizontal line within the box represents the median and horizontal lines outside the box represent minima and maxima. Additionally, dots represent outliers that are located more than 1.5 times the interquartile distance above or below the box in Fig. 3 . The 5\%fractile values were calculated (i) assuming infinite sample size and (ii) according to EN 14358 (2016) accounting for the sample size.

Considering only the beams of strength class GL48c (boxes with grey fill), a significant decrease in strength with increasing beam height is observed (Fig. 3a). For beams with a height of $200 \mathrm{~mm}$, bending strengths of up to $96 \mathrm{MPa}$ were achieved. The pronounced size effect can be explained by the increasing amount of potentially weak points, especially of finger joints, in the highly stressed outer zone of the beams.

When analysing the test results of the series with a beam height of $400 \mathrm{~mm}$, the differences in bending strength are very small between the strength classes GL40c, GL48c and GL55c. This finding is attributed to the influence of the finger joints, which were identified as predominant cause of fracture and limiting the strength of the beams independent of the strength class. Assuming infinite sample size, the test results exceeded the targeted characteristic values (5\%-fractile values) of bending strength of $40 \mathrm{MPa}, 48 \mathrm{MPa}$ and $55 \mathrm{MPa}$ in all strength classes. When introducing a penalty factor according to EN 14358 (2016) to account for the actual number of specimens tested per sample, for beams with heights higher than the reference height of $400 \mathrm{~mm}$ due to the size effect (Equation 4) and the small sample size the target values of the strength class GL48 are not met. The 
GL55 sample even for beams with heights of $400 \mathrm{~mm}$ revealed $5 \%$-fractile values $f_{\mathrm{m}, \mathrm{k}, \mathrm{EN} 14358}$ lower than the target value. In order to be able to produce GLT of strength class GL55, the process parameters for finger jointing (in particular the geometrical properties of the finger joint profile) would have to be optimized.
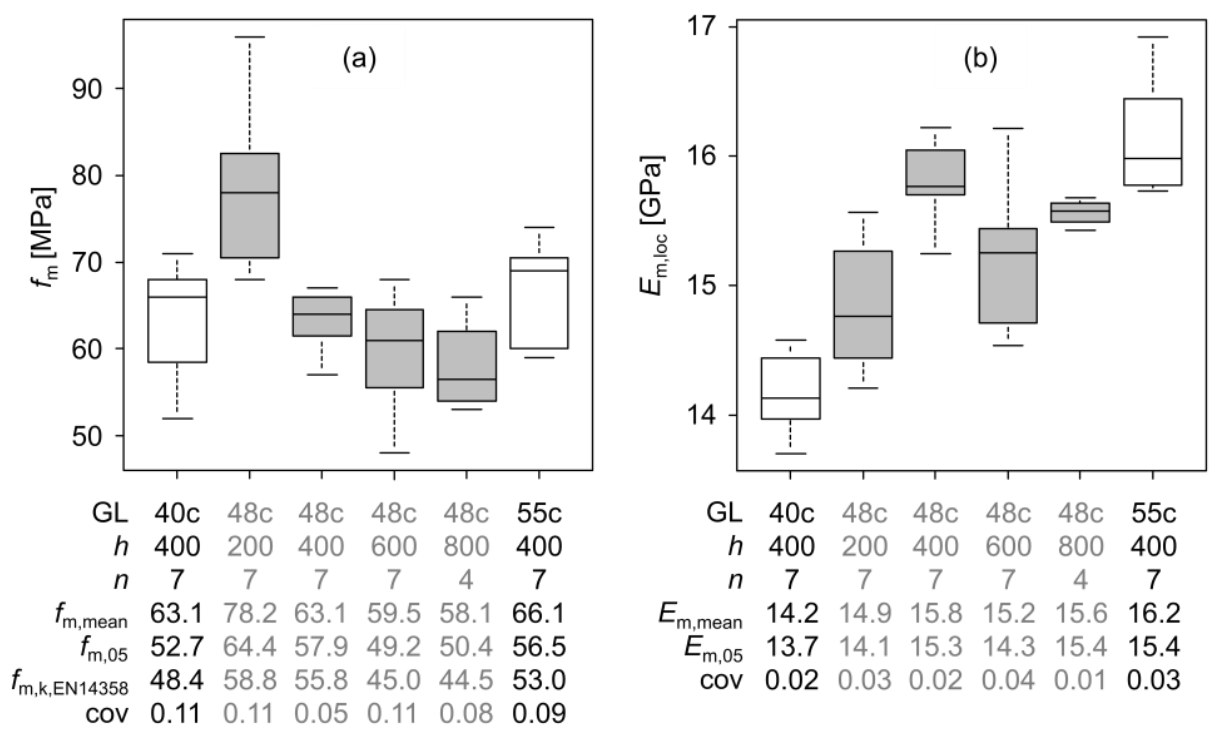

Fig. 3 Bending strength $f_{m}(a)$ and local bending MOE $E_{m, l o c}(b)$ of the tested GLT specimens of strength classes GL40c, GL48c and GL55c. Beam heights of 200, 400, 600 and $800 \mathrm{~mm}$ were investigated ( $u=8 \pm 2 \%$ ).

The coefficient of variation (cov) is around 0.10 in all series, except in series GL48c $/ h=400 \mathrm{~mm}$ $(\operatorname{cov}=0.05)$. For softwood GLT, Brandner and Schickhofer (2008) report a cov of $0.10-0.20$. Fink (2014) found cov of 0.14 and 0.13 for softwood GLT beams of strength classes GL24h and GL36h, respectively. In the JCSS Probabilistic Model Code (2006), a cov of 0.15 is listed for $f_{\mathrm{m}, \mathrm{g}}$ of softwood GLT. The smaller cov of beech GLT found in this project may be due to (i) differences in the strength grading procedures and (ii) the predominant role of the finger joint strength with respect to the bending strength of beech GLT.

Based on the experimental and additional numerical investigations (Ehrhart 2019), the size effect in bending can be described with Equation 4 with an upper strength limit at a reference height of $400 \mathrm{~mm}$. As hardly any finger joints were present in the outermost laminations of the beams with a height of $200 \mathrm{~mm}$, the results of the respective test series were not accounted for when investigating the size effect.

$$
f_{\mathrm{m}, \mathrm{g}, \mathrm{k}}=\min \left\{f_{\mathrm{m}, \mathrm{g}, \mathrm{k}, \mathrm{ref}} \cdot\left(\frac{400}{h}\right)^{0.14} ; f_{\mathrm{m}, \mathrm{g}, \mathrm{k}, \mathrm{ref}}\right\}
$$

Significant differences between the strength classes can be observed regarding the bending MOE. The calculated mean values of the local bending MOE are $E_{\mathrm{m}, \text { loc, mean }}=14.2 \mathrm{GPa}$ (GL40c), $15.3 \mathrm{GPa}$ (GL48c average over all heights) and 16.2 GPa (GL55c) and can be very well estimated based on the dynamic MOE determined during strength grading of the laminations. According to EN 384 (2019), the (local) bending MOE of softwood GLT may be calculated based on the global bending MOE by means of Equation 5. For tropical hardwoods and chestnut, Ravenshorst and van de Kuilen (2010) reported ratios between the local and global MOE of 1.16 and 1.14, respectively. Based on the results found in the present project, Equation 6 was found to describe the relationship between the local and the global MOE best for European beech GLT (coefficient of determination, $r^{2}=0.88$ ).

$$
E_{\mathrm{m}, \mathrm{loc}, \mathrm{EN} 384}=1.30 \cdot E_{\mathrm{m}, \mathrm{glob}}-2.60
$$

$$
E_{\mathrm{m}, \text { loc,Beech }}=1.17 \cdot E_{\mathrm{m}, \mathrm{glob}}-1.89
$$


In Fig. 4, the global and local MOE are plotted. For comparison purposes, the relation specified in EN 384 (2019) (Equation 5), the one proposed by Ravenshorst and van de Kuilen (2010) and the relation found in the current experiments (Equation 6) are plotted.

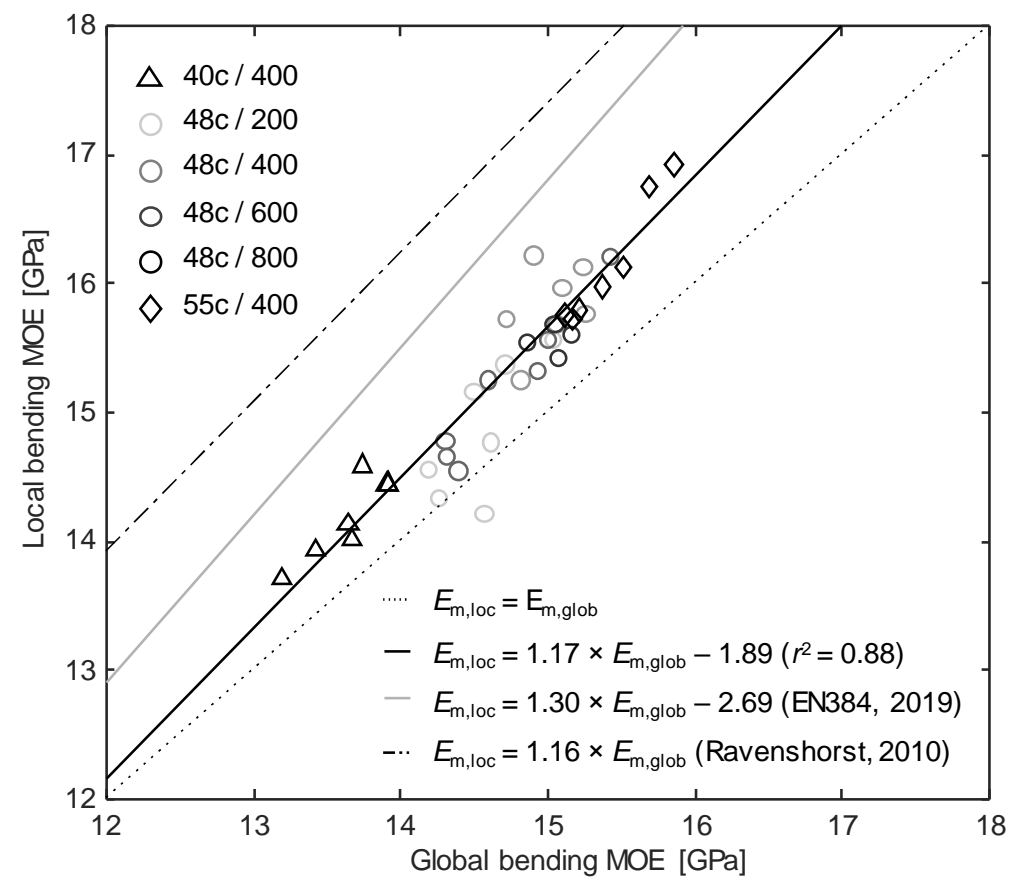

Fig. 4 Local vs. global bending MOE: Experimental data and relationship determined in the project and comparison with the relationship specified in EN 384 (2019) and the one published in Ravenshorst and van de Kuilen (2010).

\subsection{Tensile strength and MOE parallel to the grain}

\subsubsection{Material and methods}

In order to evaluate the tensile strength parallel to the grain of European beech GLT, tests were conducted on lamination bundles. Each specimen consisted of three laminations. The cross-section dimensions were $160 \times 75 \mathrm{~mm}^{2}$ and the free testing length was $3.54 \mathrm{~m}$ (i. e. $22.125 \mathrm{~b}$ ). The number of finger joints per specimen was between four and eight and on average 5.9. All specimens, in each of the three laminations, contained at least one finger joint within the free testing length. For each of the target strength classes GL55h (consisting of T50 laminations), GL48h (T42) and GL40h (T33), seven specimens were tested. The tensile strength $\left(f_{t, 0}\right)$ and the tensile $\operatorname{MOE}\left(E_{t, 0}\right)$ parallel to the grain were determined in the tests. Further information on this test series is available in Ehrhart (2019).

In addition, it was investigated whether tensile tests on lamination bundles are suitable for supplementing or even replacing the time-consuming and much more expensive four-point bending tests in future. In bending tests, failure predominantly occurs in the outermost, tensile-stressed laminations. By "cutting out" the highly stressed edge area of a beam and conducting a tensile test, material savings of about $95 \%$ per test would be possible. Assuming that the height of the critical zone is $1 / 8$ of the beam's height $(h)$, i.e., the part of the cross-section in which the bending stress $\sigma_{\mathrm{m}} \geq 0.75 \sigma_{\max }$, and its length is $6 h$, i.e., the inner distance between the force application points in bending tests according to EN 408 (2012), the volume of the tension test specimen is 1/24 (4.2\%) of the specimen's volume in a bending test. The tests were conducted only on specimens consisting of 3 laminations, i.e. representing a beam with the reference height $h=600 \mathrm{~mm}$. Hence, no conclusions regarding the evaluation of size effects in bending by means of tensile tests can be drawn. 


\subsubsection{Results and discussion}

The resulting tensile strength $\left(f_{t, 0}\right)$ and tensile $\operatorname{MOE}\left(E_{t, 0}\right)$ parallel to the grain determined in the tension tests on beech GLT lamination bundles are summarised in Table 3 grouped by strength class. The mean and $5 \%$-fractile values of strength and MOE are listed. The characteristic values of the tensile strength of the specimens of strength classes T50, T42 and T33 exceed the target fractile values of the respective strength classes with $52.9 \mathrm{MPa}$ (>50 MPa), $44.3 \mathrm{MPa}(>42 \mathrm{MPa})$ and 36.6 $\mathrm{MPa}$ (> $33 \mathrm{MPa}$ ). In EN 14080 (2013), the ratio of the characteristic tensile strength parallel to the grain and the characteristic bending strength is defined as $f_{\mathrm{t}, 0, \mathrm{~g}, \mathrm{k}} / f_{\mathrm{m}, \mathrm{g}, \mathrm{k}}=0.8$ for GLT made of softwood and poplar. Compared to the nominal bending strengths of $55 \mathrm{MPa}, 48 \mathrm{MPa}$ and $40 \mathrm{MPa}$, ratios $f_{\mathrm{t}, 0, \mathrm{~g}, \mathrm{k}} / f_{\mathrm{m}, \mathrm{g}, \mathrm{k}}$ of 0.96 (GL55), 0.92 (GL48) and 0.92 (GL40) were found in this project, exceeding the ratio specified in EN 14080 (2013).

With a value of $15.5 \mathrm{GPa}$, the mean MOE in strength class GL48h (specimens of all beam heights considered) is only slightly higher than that of strength class GL40h (15.2 GPa). Compared to the results of the bending tests (GL48c, all beam heights: $15.3 \mathrm{GPa} / \mathrm{GL} 40 \mathrm{c}$ : $14.2 \mathrm{GPa}$, Fig. 3b), the MOE determined for GL40h is above the average and the MOE determined for GL48h is representative. Amounting to $17.0 \mathrm{GPa}$, the mean MOE for strength class GL55h is significantly higher compared to the mean value found in the bending tests (GL55c: 16.2 GPa, Fig. 3b).

The analysis of the failure patterns of the tensile tests showed that at least one finger joint was involved in the failure of all test specimens. In some specimens, failure of one or more finger joints was observed in combination with a wood fracture close to a knot. Fracture patterns, in which finger joints in all three layers combined led to failure, were observed particularly in specimens of strength class GL55h. Hence, the tensile tests on the lamination bundles confirmed the results of the bending tests letting conclude the finger joints to limit the bending strength of the GLT.

Table 3 Mean and $5 \%$-fractile values of tensile strength $\left(f_{t, 0}\right.$, in MPa) and tensile MOE ( $E_{t, 0}$, in GPa) parallel to the grain determined in tensile tests on beech GLT specimens of strength classes GL55h, GL48h and GL40h with three laminations $(u=8 \pm 2 \%)$.

\begin{tabular}{llccc}
\hline & Symbol & $\begin{array}{c}\text { GL55h } \\
=\mathbf{T 5 0}\end{array}$ & $\begin{array}{c}\text { GL48h } \\
=\mathbf{T 4 2}\end{array}$ & $\begin{array}{c}\text { GL40h } \\
=\mathbf{T 3 3}\end{array}$ \\
\hline Number of specimens & $n$ & 7 & 7 & 7 \\
\hline Tensile strength, mean value & $f_{\mathrm{t}, 0, \text { mean }}$ & 57.7 & 53.3 & 43.7 \\
Tensile strength, 5\%-fractile value & $\mathrm{f}_{\mathrm{t}, 0,05}$ & 52.9 & 44.3 & 36.6 \\
Coefficient of variation [-] & cov & 0.05 & 0.09 & 0.10 \\
\hline Tensile MOE, mean value & $E_{\mathrm{t}, 0, \text { mean }}$ & 17.0 & 15.5 & 15.2 \\
Tensile MOE, 5\%-fractile value & $E_{\mathrm{t}, 0,05}$ & 16.3 & 14.7 & 13.9 \\
Coefficient of variation [-] & cov & 0.03 & 0.03 & 0.06 \\
\hline
\end{tabular}

4.3 Compressive strength and MOE parallel to the grain

\subsubsection{Material and methods}

Compression tests parallel to the grain according to EN 408 (2012) were performed on European beech GLT specimens with quadratic cross-sections of the dimensions $150 \times 150 \mathrm{~mm}^{2}$, $200 \times 200 \mathrm{~mm}^{2}$ and $280 \times 280 \mathrm{~mm}^{2}$. The lengths of the specimens were six times the cross-section width and, thus, 900,1200 and $1680 \mathrm{~mm}$, respectively. The tested specimens belonged to the target strength classes GL55h (assembled with T50 laminations), GL48h (T42) and GL40h (T33). Each sample consisted of seven specimens.

\subsubsection{Results and discussion}

The mean values of compressive strengths $\left(f_{\mathrm{c}, 0, \text { mean }}\right)$ are very similar in all series and lie between 58.2 MPa (GL48h/280 mm) and 65.8 MPa (GL55h/200 mm) (Fig. 5a). When comparing the strength 
classes GL40h $\left(f_{\mathrm{c}, 0, \text { mean }}=60.4 \mathrm{MPa}\right)$, GL48h $\left(200 \mathrm{~mm}: f_{\mathrm{c}, 0, \text { mean }}=63.8 \mathrm{MPa}\right)$, and GL55h $\left(f_{\mathrm{c}, 0, \text { mean }}=\right.$ $65.8 \mathrm{MPa}$ ), a small (+3 to $+6 \%$ ) increase in compressive strength parallel to the grain for specimens of higher strength classes was determined. The analysis of the test results of the specimens of strength class GL48h with different cross-section size revealed no clear trend regarding size effect. These results correspond well with those reported by Westermayr et al. (2018). Although the majority of the beech laminations tested by Westermayr et al. were of very low quality, the authors report compressive strengths between 49.7 and $70.8 \mathrm{MPa}\left(f_{\mathrm{c}, 0, \text { mean }}=57.0 \mathrm{MPa}, u \approx 12 \%\right)$ for the 60 specimens tested.

In addition to the high level of compressive strength parallel to the grain and the low variation of the test results, the failure behaviour is particularly noticeable. Local compression of fibres, often in zones with finger joint accumulations, local fibre deviations and knots, lead to a markedly ductile failure behaviour.

The mean value of the compressive $\operatorname{MOE}\left(E_{\mathrm{c}, 0, \text { mean }}\right)$ parallel to the grain determined on the specimens of strength class GL40h is $15.1 \mathrm{GPa}$, for specimens of grade GL48h $15.7 \mathrm{GPa}$ (all geometries), and for those of grade GL55h 17.0 GPa (Fig. 5b). The marked differences in MOE between the different strength grades most likely results from the strength grading process, in the course of which the dynamic MOE - a very good indicator for the static MOE - is considered.
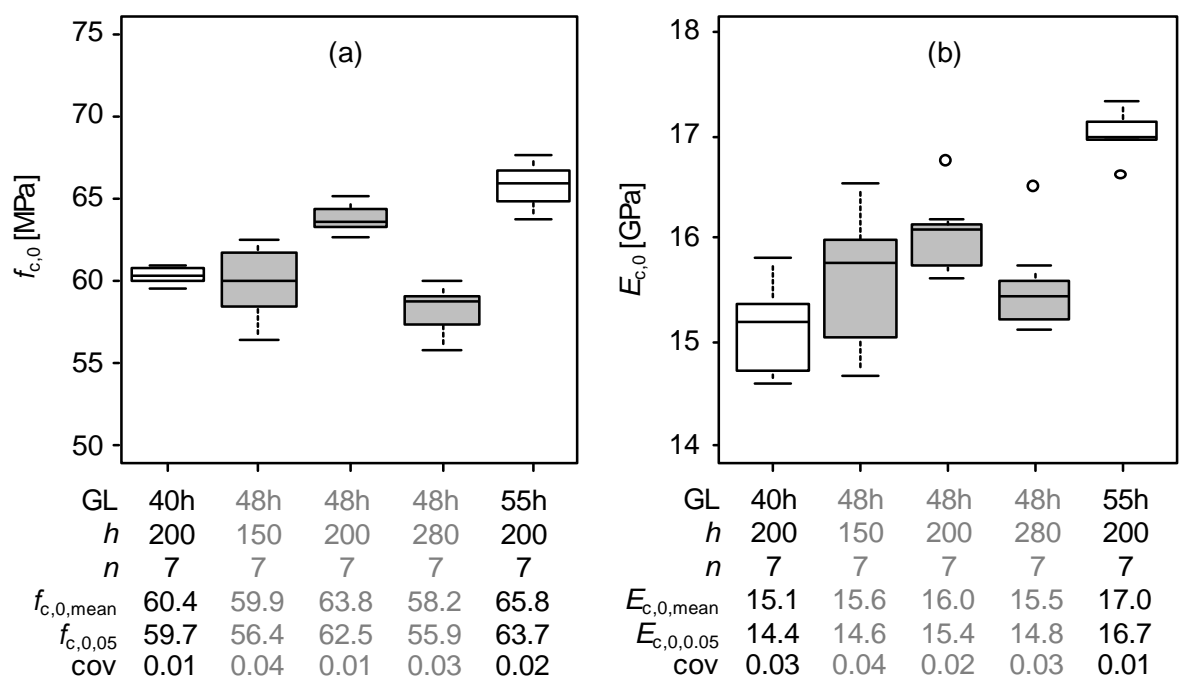

Fig. 5 Compressive strength $f_{c, 0}(\mathrm{a})$ and compressive MOE $E_{\mathrm{c}, 0}$ (b) parallel to the grain of the tested GLT specimens of strength classes GL40h, GL48h and GL55h with cross-section dimensions of $150 \times 150$, $200 \times 200$ and $280 \times 280 \mathrm{~mm}^{2}(u=8 \pm 2 \%)$.
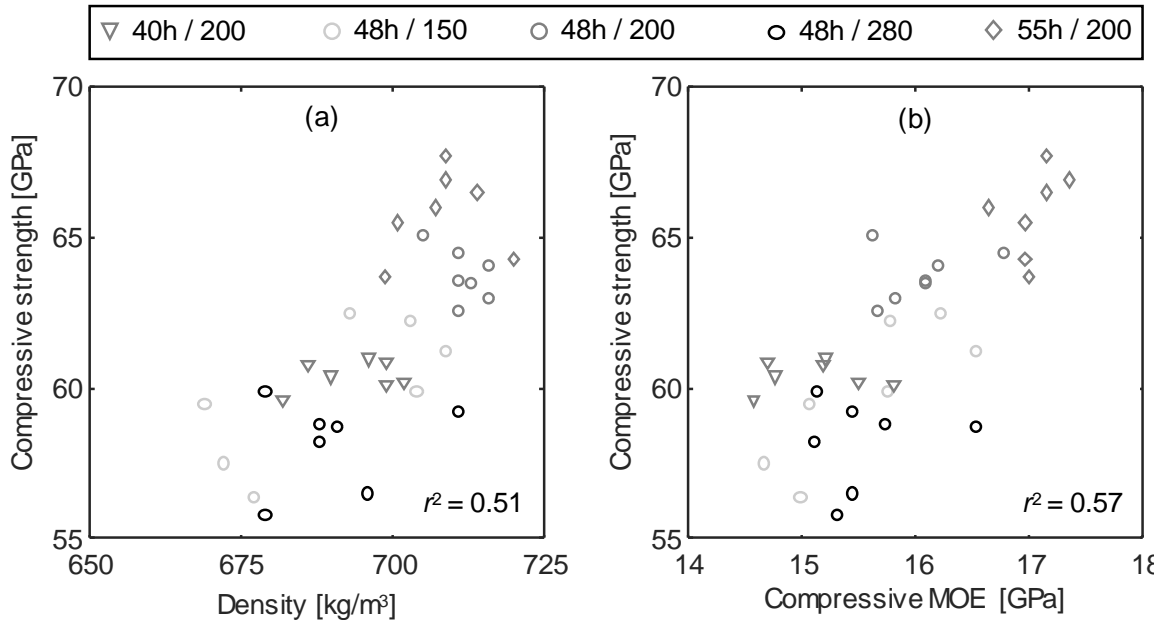

Fig. 6 Relationship between density and compressive strength parallel to the grain (a) and between compressive MOE and compressive strength parallel to the grain (b). 
A coefficient of determination of $r^{2}=0.51$ was found for the correlation between density and compressive strength parallel to the grain (Fig. 6a). The correlation between the compressive MOE and the compressive strength parallel to the grain is even higher $\left(r^{2}=0.57\right.$, Fig. $\left.6 \mathrm{~b}\right)$. If both the density $(\rho)$ and the $\operatorname{MOE}\left(E_{c, 0}\right)$ have been determined by any non-destructive measurement in advance, the compressive strength parallel to the grain of European beech GLT can be estimated using Equation 7 with a coefficient of determination $r^{2}=0.65$.

$$
f_{\mathrm{c}, 0}=-30.2+8.61 \cdot \rho \cdot 10^{-2}+2.00 \cdot E_{\mathrm{c}, 0} \cdot 10^{-3}
$$

\subsection{Shear strength and modulus}

\subsubsection{Material and methods}

For the determination of shear strength of full-size GLT beams, to date, no harmonized test procedure and set up is available in European standards. Furthermore, according to the current version of the European standard for the design of timber structures Eurocode 5 (2010), size effects in shear are not considered, disregarding numerous studies that confirmed the influence of the size of the stressed wood volume on the shear strength (e.g. Keenan 1974; Longworth 1977; Foschi and Barrett 1980; Colling 1986; Rammer et al. 1996; Gehri 2010 and Brandner et al. 2012).
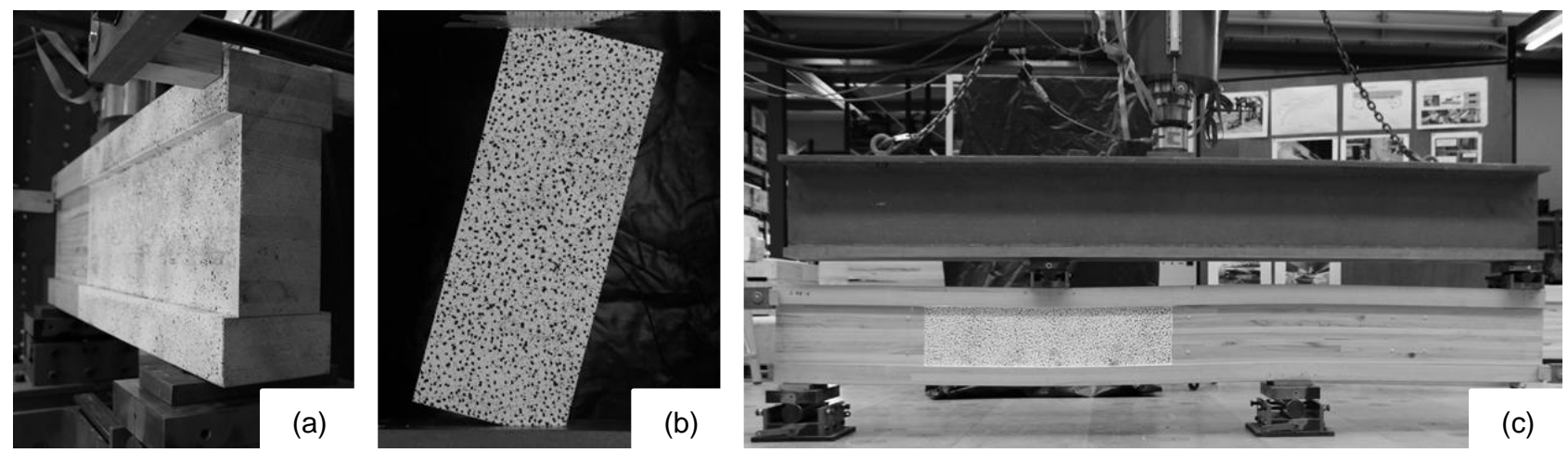

Fig. 7 Short span three-point bending test (type 3P) (a), EN 408-alike compression shear test (type EN408) (b) and asymmetric four-point bending test (type 4P) (c) in the style as presented by Basler et al. (1960).

In order to (i) investigate the shear strength of European beech GLT, (ii) to assess the influence of the size of the stressed wood volume on the shear strength and (iii) to evaluate the influence of the test configuration on the shear strength, three different test configurations were adopted in this project (Fig. 7). Furthermore, specimens of different sizes in terms of cross-section dimensions and lengths were tested. Specimens belonging to the strength classes GL48c and GL55c were investigated. However, aiming at reducing the probability of premature bending failures, the outermost laminations were always of strength grade T50.

Some 29 of the 42 shear tests were conducted using a short-span three-point bending test configuration with a span of 2.5 times the beam height (type 3P, Fig. 7a). This test configuration is similar to the one used by Büeler (2011) and Steiger and Gehri (2011). Glued-in steel rods were used to transfer the forces at the load application points and at the supports. As described by Steiger and Gehri (2011), accompanying compressive stresses perpendicular to the grain occur in this test configuration, contributing to an apparently higher shear strength. Beam heights of 200, 400 and $600 \mathrm{~mm}$ were investigated. In 24 of the above mentioned sample of 29 tests, specimens with an Ishaped cross-section were investigated in order to increase the probability of shear failures and decrease the number of bending failures (web width $=0.75 \times$ girder width, girder height $=$ $0.20 \times$ beam height). Five specimens were tested with rectangular cross-sections $\left(400 \times 160 \mathrm{~mm}^{2}\right)$.

For comparative purposes, six specimens were tested with an EN 408-alike compression-shear test configuration (type EN408, Fig. 7b). The cross-section dimensions of these specimens were $200 \times 120 \mathrm{~mm}^{2}$ and the length was $520 \mathrm{~mm}$. Another seven specimens were tested with a newly developed asymmetric four-point bending test configuration (type 4P, Fig. 7c), which is based on a 
shear test configuration presented by Basler et al. (1960). Further information on all shear test setups and the measurements is available in Ehrhart et al. (2018c) and Ehrhart (2019).

\subsubsection{Results and discussion}

Not in all tests, shear failures could be achieved. Consequently, censoring of data was considered in the data analysis, following the recommendations by Steiger and Köhler (2005). In 29 of 31 tests on specimens with I-shaped cross-sections, a shear failure could be achieved (percentage of shear failures: $\eta_{\text {shear }}=94 \%$ ). Compared to tests by Lam et al. (1995) on softwood GLT ( $\left.\eta_{\text {shear }} \approx 40 \%\right)$ and own tests with rectangular cross-sections $\left(\eta_{\text {shear }} \approx 20 \%\right.$ ), the proportion of shear failures when using I-shaped cross-sections is much higher and thus this type of cross-section is advisable when investigating specimens with particularly high shear strength, as already recommended by, for example, Larsen (1987) and Schickhofer (2001). In the EN 408-alike shear tests, mostly compression failures were observed. The resulting shear strengths $\left(f_{\mathrm{v}}\right)$ for the different test configurations, cross-section shapes, beam heights and strength classes are shown in Fig. 8.

Depending on the test configuration and the beam size, the shear strengths were found to be in a range of between 8 to $17 \mathrm{MPa}$. While van de Kuilen et al. (2017) reported shear strengths on a similar level $\left(f_{v, \text { mean }}=13.4 \mathrm{MPa}, \mathrm{cov}=0.12\right)$, Aicher and Ohnesorg (2011) found much lower shear strengths $\left(f_{v, \text { mean }}=6.1 \mathrm{MPa}, \mathrm{cov}=0.19\right)$. However, in about $50 \%$ of the tests carried out by Aicher and Ohnesorg, a bondline failure occurred, indicating that the shear strength of the used adhesive system was the limiting factor regarding the shear strength of the GLT specimen.

In agreement with the test results published by Schickhofer (2001), no significant difference in shear strength was found for the different strength classes investigated. However, digital image correlation measurements showed that failure had often been initiated in zones with local stress concentrations near knots and bark inclusions.

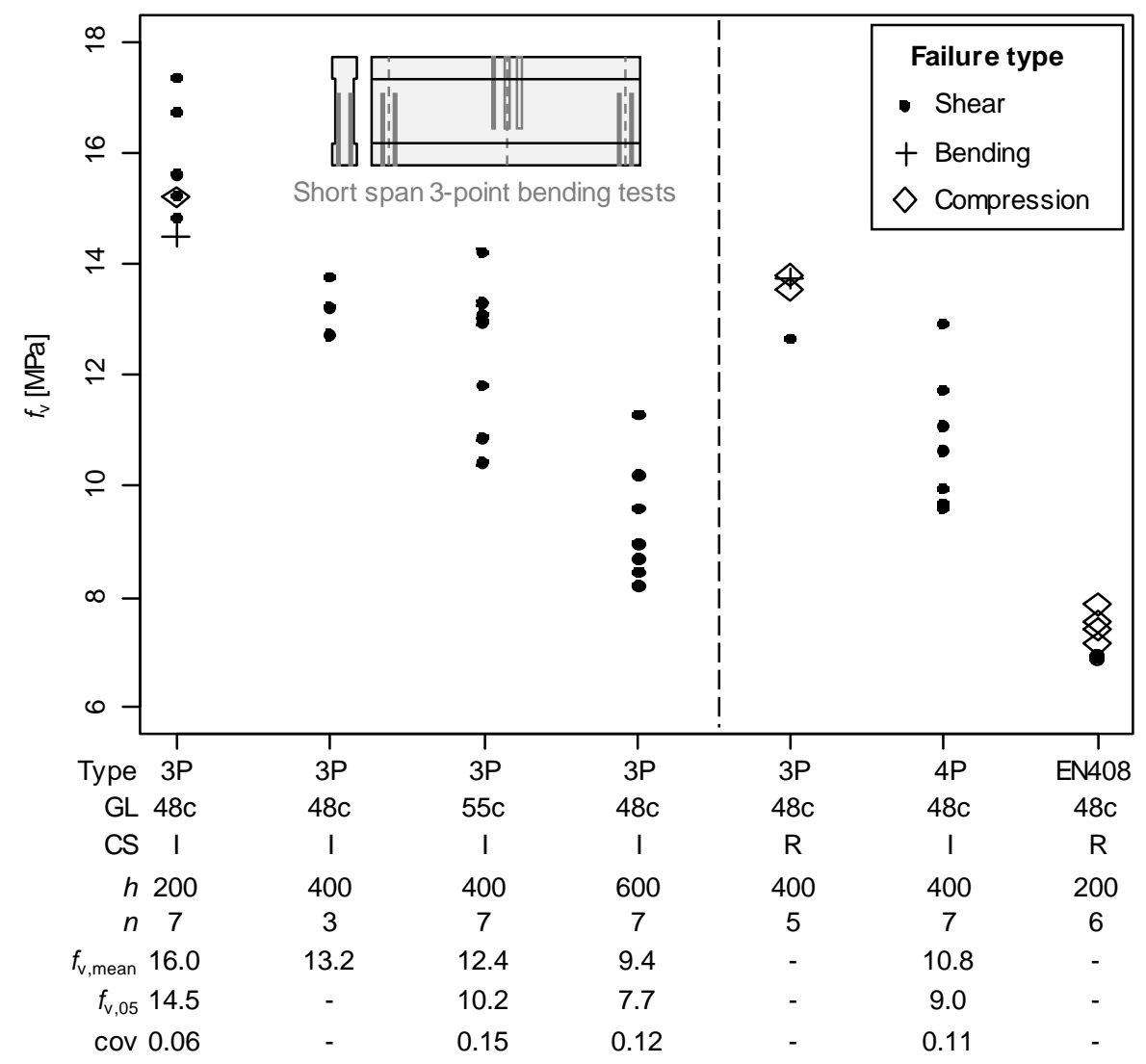

Fig. 8 Shear strength grouped by test configuration type (type), strength class (GL), cross-section type (CS) and beam height $(h)$. Censoring of the data was taken into account when analysing the test results. The markers indicate the type of failure $(u=8 \pm 2 \%)$. 
A pronounced size effect was observed, i.e., for increasing beam heights, the mean and characteristic values of shear strength decrease significantly. This finding is consistent with previous studies, in which an influence of the beam height (Brandner et al. 2012), the shear area (Keenan 1974; Gehri 2010; Rammer et al. 1996; Soltis and Rammer 1994) or the beam volume (Longworth 1977; Colling 1986; Foschi and Barrett 1980) on the shear strength had been reported. Ehrhart (2019) presented a volume-based approach for the consideration of the size effect. Assuming a conservative ratio between bending and shear strength and identifying critical loading conditions, the volume based approach can be simplified to Equation 8 based on the beam height.

$$
f_{\mathrm{v}, \mathrm{g}, \mathrm{k}}=\min \left\{6.0 \cdot\left(\frac{400}{h}\right)^{0.4} ; 6.0\right\}
$$

In 71 shear field measurements, a mean value of shear modulus $G_{g \text {,mean }}=1.17 \mathrm{GPa}$ and a $5 \%$ fractile value of $G_{g, 05}=0.97 \mathrm{GPa}$ were determined (cov $=0.11$ ). These values are $25 \%$ higher compared to the values reported by Büeler (2011). However, Büeler used beech laminations of very low quality with a moisture content of $u \approx 12 \%$. In the technical approval Z-9.1-679 (2009) for European beech GLT, a mean value of shear modulus of $1.00 \mathrm{GPa}$ and a $5 \%$-fractile value of $0.80 \mathrm{GPa}$ are indicated.

The asymmetric four-point bending test presented in this paper is based on the configuration used by Basler et al. (1960) for the investigation of web buckling of welded steel plate girders. It has proven to be very suitable for determining the shear strength of GLT. Shear failures occurred in all tests and the shear field is almost free of simultaneously acting perpendicular to grain stresses. The test configuration is a realisation of a loading situation in practice (multi-span beam) where shear stresses are most likely governing the design. Given a certain shear force, the simultaneously acting maximum bending moment and the forces to be introduced are considerably lower compared to a three-point bending test. Consequently, shear failures are more likely to occur, even without the need of changing from the rectangular to an I-shaped cross-section. Thus, this test configuration should be further investigated, applied and, ultimately, evaluated to be included in the test standard EN 408 (2012).

\section{Mechanical properties of European beech GLT}

Based on the experimental investigations presented in this paper and additional numerical simulations targeting the bending and tensile strength parallel to the grain (Ehrhart 2019), the mechanical properties and densities summarised in Table 4 have been determined for European beech (Fagus sylvatica L.) GLT of the strength classes GL40, GL48 and GL55 with combined and homogeneous layups (Fig. 2). The presented values are valid for a wood moisture content of $u=8 \pm 2 \%$ and refer to a reference height of $400 \mathrm{~mm}$. Size effects on the bending, tension and shear strength shall be considered using Equation $4\left(f_{\mathrm{m}, \mathrm{g}, \mathrm{k}}\right.$ and $\left.f_{\mathrm{t}, 0, \mathrm{~g}, \mathrm{k}}\right)$ and Equation $8\left(f_{\mathrm{v}, \mathrm{g}, \mathrm{k}}\right)$.

Whilst the MOE in tension and compression parallel to the grain were almost identical for all strength classes GL40h (mean values of 15.2 vs. $15.1 \mathrm{GPa}$ ), GL48h (15.5 vs. $15.7 \mathrm{GPa}$ ) and GL55h (17.0 vs 17.0 GPa), slightly lower values were found for the local bending MOE (14.2, 15.3 and 16.2 GPa). However, as the range of bending MOE within strength class GL48c was between 14.2 and 16.2 $\mathrm{GPa}$, these differences can rather be attributed to the natural variation of the material properties than to the type of loading. Whereas this finding is of interest in research, the differences are small and hence, the design of beech GLT structural members in practice may be based on only one MOE value, which is valid independent of the loading situation. The MOE values listed in Table 4 additionally take into account the results of numeric simulations (Ehrhart 2019).

Table 4 Mechanical properties (strength in MPa; MOE and shear moduli in GPa) and density (in $\mathrm{kg} / \mathrm{m}^{3}$ ) of European beech (Fagus sylvatica L.) GLT of strength classes GL40, GL48 and GL55 with homogeneous and 
combined layups according to Fig. 2. The specified values refer to a beam height of $400 \mathrm{~mm}$ and a moisture content of $u=8 \pm 2 \%$.

\begin{tabular}{|c|c|c|c|c|c|c|c|}
\hline \multirow{2}{*}{ Property } & \multirow{2}{*}{ Symbol } & \multicolumn{6}{|c|}{ GL strength class } \\
\hline & & $40 c$ & $40 \mathrm{~h}$ & $48 c$ & $48 h$ & $55 c$ & $55 h$ \\
\hline Bending strength & $f_{\mathrm{m}, \mathrm{g}, \mathrm{k}}$ & 40.0 & 40.0 & 48.0 & 48.0 & 55.0 & 55.0 \\
\hline Tension strength & $f_{\mathrm{t}, 0, \mathrm{~g}, \mathrm{k}}$ & 26.0 & 32.0 & 30.0 & 38.4 & 36.5 & 44.0 \\
\hline Compression strength & $f_{c, 0, g, k}$ & 40.0 & 45.0 & 45.0 & 50.0 & 50.0 & 55.0 \\
\hline Shear strength & $f_{v, g, k}$ & \multicolumn{6}{|c|}{6.0} \\
\hline \multirow{2}{*}{ Modulus of elasticity } & $E_{0, g, \text { mean }}$ & 14.0 & 14.2 & 15.2 & 15.4 & 16.4 & 16.6 \\
\hline & $E_{0, g, 05}$ & 13.0 & 13.2 & 14.2 & 14.4 & 15.4 & 15.6 \\
\hline \multirow{2}{*}{ Shear modulus } & $G_{g, \text { mean }}$ & \multicolumn{6}{|c|}{1.10} \\
\hline & $G_{g, 05}$ & \multicolumn{6}{|c|}{0.90} \\
\hline \multirow{2}{*}{ Density } & $\rho_{\mathrm{g}, \mathrm{k}}$ & \multicolumn{6}{|c|}{660} \\
\hline & $\rho_{\mathrm{g}, \text { mean }}$ & \multicolumn{6}{|c|}{690} \\
\hline
\end{tabular}

\section{Conclusion}

In the presented study, based on extensive experimental and numerical investigations, it was shown that it is possible to produce GLT of strength classes GL40, GL48 and GL55 with homogeneous and combined layups from European beech wood. Rules for a combined visual/machine strength grading approach were developed and presented. The knot size, described by the total knot area ratio, fibre deviations and the dynamic modulus of elasticity were determined to have the largest influence on the tensile strength and stiffness parallel to the grain of single laminations. For further improving the quality of the strength estimation and in order to get a more efficient strength grading process, a noncontact method for the determination of the fibre orientation was developed within this project.

The finger-joint strength and the bondline strength and durability were tested and evaluated according to current European standards. Although these standards were developed for softwood GLT, all requirements were fulfilled using optimised adhesive systems and process parameters. Extensive experimental investigations on European beech GLT have shown that the mechanical properties are considerably higher compared to softwood GLT. Using European beech wood for structural applications allows to extend the range of GLT from currently GL32 (according to EN 14080, 2013) up to GL55 and, thus, to increase the bending, tensile, compressive and shear strengths by more than $70 \%$. However, for the production of European beech GLT of strength class GL55 finger jointing of the boards has to be optimized, particularly regarding the profile of the finger joints.

Similar to prescriptions in Eurocode 5 (2010), Equation 6 was developed to consider size effects on the bending strength of European beech GLT. However, compared to Eurocode 5 (2010), a slightly higher exponent of 0.14 (instead of 0.10 ) was found. Furthermore, it is suggested not to increase the bending strength for beams smaller than the reference height, but to decrease the strength of beams larger than the reference height. Additionally, Equation 8 was presented for consideration of the size effect in shear, taking into account results of this project and previous studies confirming the influence of the size of the stressed wood volume on the shear strength.

The asymmetric four-point bending test presented in this paper has proven to be very suitable for determining the shear strength of GLT. Shear failures occurred in all tests and the shear field is almost free of simultaneously acting perpendicular to grain stresses. 


\section{Acknowledgments}

The authors gratefully acknowledge the funding received from the Swiss Federal Office for the Environment FOEN within the framework of the Aktionsplan Holz. Gratitude for the excellent cooperation is expressed to the Swiss sawmillers Corbat SA, Konrad Keller AG, Richard Lötscher $A G$ and Koller AG, to the suppliers of the strength grading devices MiCROTEC and Brookhuis and to the adhesive experts of Henkel Engineered Wood Adhesives. Finally, the assistance of the technicians at Empa and ETH Zürich in preparing and carrying out the experiments as well as the input and support by Holzindustrie Schweiz, the hardwood GLT specialists of neue Holzbau AG, who took care of producing the GLT specimens, and the experts Prof. em. E. Gehri and M. Zimmermann are thankfully acknowledged.

\section{Conflict of interest statement}

On behalf of all authors, the corresponding author states that there is no conflict of interest.

\section{References}

Aicher S, Höfflin L, Behrens W (2001) A study on tension strength of finger joints in beech wood laminations. Otto-GrafJournal, 12, pp. 169-186.

Aicher S, Ohnesorg D (2011) Shear strength of glued laminated timber made from European beech timber. European Journal of Wood and Wood Products, 69, pp. 143-154. doi: DOI 10.1007/s00107-009-0399-9.

BAFU, BFE, SECO (Publisher) (2017) Ressourcenpolitik Holz - Strategie, Ziele und Aktionsplan Holz (in German; Wood Resource Policy - Strategy, Objectives and Wood Action Plan). Federal Office for the Environment FOEN, Bern, Switzerland.

BAFU (Publisher) (2018) Jahrbuch Wald und Holz 2018 - Umwelt-Zustand Nr. 1830 (in German; Swiss Statistical Yearbook of Forestry). Federal Office for the Environment FOEN, Bern, Switzerland.

Blaß HJ, Denzler J, Frese M, Glos P, Linsenmann P (2005) Biegefestigkeit von Brettschichtholz aus Buche - Karlsruher Berichte zum Ingenieurholzbau - Band 1 (in German; Bending strength of beech glulam). Karlsruhe, Germany: Universitätsverlag Karlsruhe.

Bogensberger T, Schickhofer G, Unterwieser H (2006) The mechanical inconsistency in the evaluation of the modulus of elasticity according to EN 384. CIB-W18 Meeting Thirty-Nine. Florence, Italy. Paper 39-21-2.

Brandner R, Gatternig W, Schickhofer G (2012) Determination of shear strength of structural and glued laminated timber. CIB - Meeting Forty-Five. Växjö, Sweden. pp. 237-254. Paper 45-12-2.

Brandner R, Schickhofer G (2008) Glued laminated timber in bending: New aspects concerning modelling. Wood Sci Technol 42, pp. 401-425. doi: 10.1007/s00226-008-0189-2.

Brändli, UB (2010) Schweizerisches Landesforstinventar - Ergebnisse der dritten Erhebung 2004-2006 (in German; Swiss National Forest Inventory - Results of the third survey 2004-2006). Eidgenössische Forschungsanstalt für Wald, Schnee und Landschaft WSL, Birmensdorf, Switzerland and Bundesamt für Umwelt, BAFU, Bern, Switzerland.

Basler K, Yen BT, Mueller JA, Thürlimann B (1960) Web buckling tests on welded plate girders. Welding Research Council Bulletin Series.

BS 4978 (1996) - Specification for Visual strength grading of softwood. BSI British Standard Institute.

Büeler M (2011) Schubverhalten von Brettschichtholzträgern aus Buche und Esche (in German; Shear behaviour of beech and ash glulam beams). Master's Thesis, ETH Zürich.

Bundesforschungszentrum für Wald bfw, Österreich (2019) Zukünftige Baumartenverteilung bis 2100 (in German; Future tree species distribution until 2100). Zuschnitt, 75, p. 14.

Clerc G, Lehmann M, Volkmer T (2017) Brettschichtholz aus Laubholz - Technische Grundlagen zur Marktimplementierung als Bauprodukt in der Schweiz - Abschlussbericht Modul 3 (in German; Hardwood glued laminated timber - Technical requirements for the market implementation as a building product in Switzerland). Biel, Switzerland.

Colling F (1986) Influence of volume and stress distribution on the shear strength and tensile strength perpendicular to grain. CIB - Meeting Nineteen, Volume 2. Florence, Italy. pp. 254-276. Paper 19-12-3.

DIN 4074-5 (2008) Strength grading of wood - Part 5 - Sawn hard wood. DIN German Institute for Standardization.

Ehrhart T, Fink G, Steiger R, Frangi A (2016) Experimental investigation of tensile strength and stiffness indicators regarding European beech timber. World Conference on Timber Engineering. Vienna, Austria. 
Ehrhart T, Steiger R, Palma P, Frangi A (2018a) Estimation of tensile strength of European beech timber boards based on the analysis of density, dynamic MOE and local fibre direction. World Conference on Timber Engineering. Seoul, Republic of Korea.

Ehrhart T, Steiger R, Frangi A (2018b) A non-contact method for the determination of fibre direction of European beech wood (Fagus sylvatica L.). Eur J Wood Prod 76(3), pp. 925-935. doi: 10.1007/s00107-017-1279-3.

Ehrhart T, Steiger R, Palma P, Frangi A (2018c) Mechanical properties of European beech (Fagus sylvatica L.) glued laminated timber. International Network on Timber Engineering Research - Meeting Fifty-One. Tallinn, Estonia. pp. 343360. Paper 51-12-4.Ehrhart T (2019) European beech glued laminated timber. Doctoral Thesis No. 26173, ETH Zürich.

Ehrhart T, Steiger R, Frangi A (2017) Impact and detection of grain direction in European beech wood. International Network on Timber Engineering Research - Meeting Fifty. Kyoto, Japan. pp. 479-482. Technical Note.

EN 302-1 (2013) Adhesives for load-bearing timber structures - Test methods - Part 1 - Determination of longitudinal tensile shear strength. CEN European Committee for Standardization.

EN 302-2 (2017) Adhesives for load-bearing timber structures - Test methods - Part 2 - Determination of resistance to delamination. CEN European Committee for Standardization.

EN 384 (2019) Structural Timber - Determination of characteristic values of mechanical properties and density. CEN European Committee for Standardization.

EN 408 (2012) Timber structures - Structural timber and glued laminated timber - Determination of some physical and mechanical properties. CEN European Committee for Standardization.

EN 1990 (2010) Basis of structural design. CEN European Committee for Standardization.

EN 14080 (2013) Timber structures - Glued laminated timber and glued solid timber - Requirements. CEN European Committee for Standardization.

EN 14358 (2016) Timber structures - Calculation and verification of characteristic values. CEN European Committee for Standardization.

EN 15425 (2017) - One component polyurethane (PUR) for load-bearing timber structures - Classification and performance requirements. CEN European Committee for Standardization.

Eurocode 5 (2010) Design of timber structures - Part 1-1: General - Common rules and rules for buildings. CEN European Committee for Standardization.

Fink G (2014) Influence of varying material properties on the load-bearing capacity of glued laminated timber. Doctoral Thesis, ETH Zurich.

Foschi RO, Barrett JD (1980) Consideration of size effects and longitudinal shear strength for uncracked beams. CIB Meeting Thirteen. Otaniemi, Finland. Paper 13-6-2.

Frühwald A, Ressel JB, Bernasconi A (2003) Hochwertiges Brettschichtholz aus Buchenholz (in German; High quality glued laminated timber made from beech wood). Hamburg, Germany.

Frühwald K, Schickhofer G (2004) Strength grading of hardwoods. World Conference on Timber Engineering - Vol. IIlb. Lahti, Finland, pp. 675-679.

Gehri E (2010) Shear problems in timber engineering - analysis and solutions. World Conference on Timber Engineering. Riva del Garda, Italy.

Glos P, Lederer B. (2000) Sortierung von Buchen- und Eichenschnittholz nach der Tragfähigkeit und Bestimmung der zugehörigen Festigkeits- und Steifigkeitskennwerte (in German; Strength grading of beech and oak sawn timber and determination of associated strength and stiffness characteristics). Munich, Germany.

Hoffmeyer P (1995) Wood as a building material, Lecture A4. In: Timber Engineering Step 1: Basis of design, material properties, structural components and joints. Centrum Hout, Almere, The Netherlands, pp A4/1 - A4/21

Hübner U (2013) Mechanische Kenngrössen von Buchen-, Eschen-und Robinienholz für lastabtragende Bauteile (in German; Material parameters of beech, ash and robinia wood for load-bearing structures). Doctoral Thesis, Graz University of Technology.

JCSS Probabilistic Model Code Part 3: Resistance Models (2006). doi: ISBN 978-3-909386-79-6.

Keenan FJ (1974) Shear strength of wood beams. Forest Products Journal, 24(9), pp. 63-70.

van de Kuilen JWG, Gard W, Ravenshorst G, Antonelli V, Kovryga A (2017) Shear strength values for soft- and hardwoods. International Network on Timber Engineering Research - Meeting Fifty. Kyoto, Japan. pp. 49-65. Paper 50-6-1.

Lam F, Yee H, Barrett JD (1995) Shear strength of Canadian softwood structural lumber. CIB - Meeting Twenty-Eight. Copenhagen, Denmark. pp. 118-134. Paper 28-6-1.

Larsen HJ (1987) Determination of shear strength and strength perpendicular to grain. CIB - Meeting Twenty. Dublin, Ireland. pp. 155-160. Paper 20-6-3 
Lehmann M, Clerc G, Lehringer C, Strahm T, Volkmer T (2018) Investigation of the bond quality and the finger joint strength of beech glulam. World Conference on Timber Engineering. Seoul, Republic of Korea.

Lindner M, Maroschek M, Netherer S, Kremer A, Barbati A, Carcia-Gonzalo J, Seidl R, Delzon S, Corono P, Kolström M, Lexer MJ, Marchetti M (2010) Climate change impacts, adaptive capacity, and vulnerability of European forest ecosystems. Forest Ecology and Management, 259(4), pp. 698-709. doi: 10.1016/j.foreco.2009.09.023.

Linsenmann P (2016) European hardwoods for the building sector (EU Hardwoods) - Final report. Available at: http://euhardwoods.eu.

Longworth J (1977) Longitudinal shear strength of timber beams. Forest Products Journal, 27(8), pp. 19-23.

Plos M, Fortuna B, Straze A, Turk G (2018) Visual Grading of Beech Wood - a Decision Tree Approach. World Conference on Timber Engineering. Seoul, Republic of Korea.

Rammer D, Soltis L, Lebow P (1996) Experimental shear strength of unchecked solid-sawn Douglas-fir. Forest Service Research Paper FPL-RP-553.

Ravenshorst G, van de Kuilen JWG (2010) Relationships between local, global and dynamic modulus of elasticity for softand hardwoods. CIB - Meeting Forty-Two. Duebendorf, Switzerland. Paper 42-10-1.

Schickhofer G (2001) Determination of shear strength values for GLT using visual and machine graded spruce laminations. CIB - Meeting Thirty-Four. Venice, Italy. pp. 383-409. Paper 34-12-6.

Schlotzhauer P, Wilhelms F, Lux C, Bollmus S (2018) Comparison of three systems for automatic grain angle determination on European hardwood for construction use. Eur J Wood Prod, 76(3), pp. 911-923. doi: 10.1007/s00107-018-1286-z.

Soltis L, Rammer D (1994) Shear strength of unchecked glued-laminated timber beams. Forest Products Journal, 44(1), pp. 51-77.

Steiger R, Gehri E (2011) Interaction of Shear Stresses and Stresses Perpendicular to the Grain. CIB - Meeting FourtyFour. Alghero, Italy, pp. 135-149. Paper 44-6-2.

Steiger R, Köhler J (2005) Analysis of censored data - examples in timber engineering research. CIB - Meeting ThirtyEight. Karlsruhe, Germany. Paper 38-17-1.

Unterwieser H, Schickhofer $\mathrm{G}$ (2011) Influence of moisture content of wood on sound velocity and dynamic MOE of natural frequency- and ultrasonic runtime measurement. Eur J Wood Prod 69(2), pp. 171-181. doi: 10.1007/s00107-010-0417-y. Weibull W (1939) A statistical theory of the strength of materials. Royal Technical University, Stockholm, Sweden.

Westermayr M, Stapel P, Van de Kuilen JWG (2018) Tensile and Compression Strength of Small Cross Section Beech Glulam Members. International Network on Timber Engineering Research - Meeting Fifty-One. Tallinn, Estonia. pp. 307322. Paper 51-12-2.

Z-9.1-679 (2009) Allgemeine bauaufsichtliche Zulassung für BS-Holz aus Buche und BS-Holz Buche-Hybridträger (in German; National technical approval for beech glulam and hybrid glulam). Studiengemeinschaft Holzleimbau eV.; DIBt Deutsches Institut für Bautechnik. 